\title{
Urgences
}

\section{Grandeur de rêve...}

\section{Marielle Sénéchal}

Numéro 4, 2e trimestre 1982

URI : https://id.erudit.org/iderudit/025063ar

DOI : https://doi.org/10.7202/025063ar

Aller au sommaire du numéro

Éditeur(s)

Urgences

ISSN

0226-9554 (imprimé)

1927-3924 (numérique)

Découvrir la revue

Citer ce document

Sénéchal, M. (1982). Grandeur de rêve... Urgences, (4), 67-70.

https://doi.org/10.7202/025063ar

Ce document est protégé par la loi sur le droit d'auteur. L'utilisation des services d'Érudit (y compris la reproduction) est assujettie à sa politique d'utilisation que vous pouvez consulter en ligne.

https://apropos.erudit.org/fr/usagers/politique-dutilisation/
Cet article est diffusé et préservé par Érudit.

Érudit est un consortium interuniversitaire sans but lucratif composé de l’Université de Montréal, l'Université Laval et l'Université du Québec à Montréal. Il a pour mission la promotion et la valorisation de la recherche. https://www.erudit.org/fr/ 
MARIELLE SÉNÉCHAL

Grandeur de rêve... 
Que j'aimerais me désallonger le cou! Ou le nez. Plutôt les deux.

A cause du plafond. Si je me penche, il descend avec moi et regarde par dessus mon épaule la rangée de cadrans qui pointent du plancher en montrant la nuque honteusement. Leurs aiguilles sont à zéro.

$\mathrm{C}^{\prime}$ est gris le mur, la poussière et la lumière éteinte. II y a ces ombres bossues et borgnes qui savent qu'un moteur a flanché... et que sont miens l'accélérateur et la pédale d'embrayage. Bien sûr... la nuit,... c'est la mère du non-dit...

II me faut mes clés! Elles sont dans ma veste... sur le dossier de ma chaise... près de mon lit...

Mon bon lit!...

...je suis peut-être parti de rien mais loin d'être revenu de tout.

La fleur qui était à ma boutonnière a disparu.

- Patron, c'est que... il me semble que les fleurs de pomme de terre doivent rester dans les champs... non?

- Elle est modeste, voyez-vous ça?... Eh bien je suis le gérant du département des appropriations et tu vas tenir ta tête haute comme si tu étais sur l'épaule de Trudeau. Compris?

Mes clés... voyons... j'étais si fatigué... je peux m'être trompé de côté et les avoir lancées sur la tête des imbéciles que je réussis (non sans peine, je l'avoue) à mettre dans ma poche. Doucement... qu'ils ne se doutent de rien.

Ni clés, ni "petits commis de bureau"! J'aurais dû m'en douter. Il se trame quelque chose. Et il fait chaud. Non, il fait froid... un peu de cognac...

Que je retrouve mes subalternes! 
Ce sont les pieds de Vincent, ses "Oxford" sûrement...

celui-là... toujours un pied près de la porte et si elle s'ouvre... (il a pris ma technique, le vaurien!)... c'est bien ma chaise qu'il veut...

...sous les grandes jambes de Martin... sa ceinture neuve...

soyons bon prince... il est jeune. Une présence physique au bureau, c'est déjà pas mal. L'important, c'est d'être à I'heure. Toujours.

...le dos et la tête de Marius...

le zélé... trrrès important de l'avoir à l'oeil... que j'entende ce qu'il complote au téléphone avec les gars du bureauchef... Le tenir loin de ma femme... parce qu'au fond de son verre, il traîne des souvenirs de la France occupée et de l'allergie à la couleur kaki qu'il m'a dessinée avec du mercurochrome...

...ce totem ne m'impressionne pas du tout!

Hé! là-bas... qui vous a dit... que faites-vous... qui a pris mes clés?

- Euh... les femmes sont là...

- Les femmes? Depuis quand les femmes comptent-elles dans ce bureau? Mes clés, vite!

Tournez vos têtes, cadrans idiots, je démarre.....................

Vrrrrrrrrrrrrrrrrrrrrrrrrrrrrrrrrrrrrrrrrrrrrrrrrrrrrrrrrrrrroum! ....PAFFFFF 
Laissez passer... laissez-moi... vous croyez que je laisserais brûler un enfant, là-haut?... laissez-moi passer!....

Ah! non!... c'est une... poupée... de coton. avec une tête, des jambes et des bras brinqueballants en coton blanc... 